\title{
ONLINE TEACHERS COMMUNITY
}

\author{
I Made Candiasa ${ }^{1}$, Ni Made Sri Mertasari ${ }^{2}$ \\ Mathematics Education Department \\ Universitas Pendidikan Ganesha \\ Singaraja, Indonesia \\ candiasa@undiksha.ac.id ${ }^{1}$, srimertasari@undiksha.ac.id ${ }^{2}$
}

\begin{abstract}
Access extension and quality improvement in education is an issue that must be addressed immediately. The government makes every endeavor to do its best, but the results are not optimal because it faced several obstacles, such as geographical, social economic and local government revenue differences. One solution that has been developed is a website named online teacher community which can facilitate the process of sharing information on the instruction. This research aimed to evaluate the effectiveness of online teacher community website. The results showed that online teacher community website could act as a medium of learning for sharing information among the teachers and become an effective medium of learning for the students. This medium could build communication link among teachers not only in one district/city, but also across districts/cities and even across the provinces. In addition, the medium could be used as a medium for school' self-evaluation so the schools could compare themselves with other schools in the quality of the instruction. Such mechanisms are expected to be able to encourage the extension of access and quality improvement in education.
\end{abstract}

Keywords- online teacher's community; access extension; quality improvement

\section{INTRODUCTION}

National education system should have the capacity to guarantee the equal opportunity for education and then ensure the improvement of the education quality. For that reason, access extension and quality improvement in education is two of the people's demands for services in education. Indonesia is an archipelago with geography condition, regional income and population conditions which are varied, so it implies the variety of development achievements, including the development in education. Such variations need to be facilitated immediately to increase the quality as well as equity in education. The solution is offered by having cross-subsidy on the experts, fund, and facilities, but that solution is relatively difficult to be implemented. Another solution which can be implemented is by providing media that allows the exchange of information to overcome the difference on geography and economic. The media that has such function is a web portal that is equipped learning facilities to establish an online teachers' community. Information and communication technology infrastructure (internet) highly supports the media.

Online learning community is a group of learning based on common interests and a commitment for collaborative learning with virtual learning environments [1]. Online learning occurs in virtually using the computer network (the Internet), so it can be used to decrease the face to face communication. The characteristics of computer mediated communication such as context-free and free of social conventions stimulate more meaningful communication, especially for students who have face to face communication disorders. Sofos \& Kostas [2] found that the involvement of the community in practical online were able to improve the ability of teachers to manage web learning that meets the standard web learning criteria. Previously, Sofos \& Kostas [2] found very few sites that meet the criteria of functional, educational, and didactic learning since the teacher only understands the web as a medium of learning. So, the teachers do not integrate web on learning in the classroom, but they use it sporadically. In addition, the teachers emphasize more on the content of teaching materials and its relevance to the learning program and produce less attention to other aspects such as flexibility performance, ergonomics, or the variability in the learning mode.

Online teacher community website gives an opportunity to the students to be able to access content from multiple sites simultaneously, either in the form of text, audio, or video. The students can interact with teachers and students from a variety of ways. Students can independently regulate their earning and teachers can improve their ability to manage learning through collaboration with colleagues. Some advanced students openly state that their learning difficulties and even express questions to colleagues from other schools that they had never known. So, students have the opportunity to access material from other environments, not only from their local environment to arise their horizons. Thus, the students can learn comfortably and directly communicate with other students and teachers online.

Online teacher community gives an opportunity for teachers to develop their own teaching materials and place them on the portal. The developed teaching materials become a tendency of e-learning today because the teachers' instructional materials developments are more accurate and interesting than the experts' [3]. Teachers and students are not only becoming the users of e-learning, but also as creators and developers of e-learning materials. Web learning is reusable, so it is very beneficial for learning design process in some 
parts only happen once. Re-use of learning design can be defined as the use of the whole or replacement document of the learning environment, activities, roles or methods [4].

To be able to assimilate the learning materials in e-learning, students develop a series of psychological processes such as perception, attention, comprehension, motivation, memory, and thinking. Therefore, the e-learning needs effective learning situations that can be developed by developing effective learning designs started from formulating learning objectives to formulate the learning assessment to help students' comfort learning atmosphere. As digital learning design, there are some design elements that must be fulfilled by e-learning, both visual design and pedagogical design, such as the page settings, systematic material, illustrations, and color. Pedagogically, several requirements must be coped in the design of digital learning as follows. 1) Simultaneously followed by competence development and transmission of knowledge. 2) Ability to facilitate the independent structure of the material, both for learning structured and unstructured learning. 3) Able to anticipate the development of effective thinking strategies. 4) Able to anticipate the varying levels of mental development [4].

Continuity of the material in the form of text, graphics, animation, or video helped creating the connections between concepts to form a new concept. In constructivism, the ability to create new knowledge that can be accessed and updated become a very important component. Furthermore, the ability to create a synthesis and an ability to build connections are necessary information in the technology era. The learning process is called connect learning (Steiner \& Ehlers, 2010). One of the effective medium used to facilitate connect learning is web learning. Steiner \& Ehlers (2010) explains that, connect learning based on connectivism, constructivism, and situational learning approach consolidate the concepts that can help to meet the learning needs of the new organized learning scenarios, learner-oriented, communicative, and social, emotional, and situational. This research developed a web portal named online teacher community that can facilitate the process of sharing information on the instruction among the teachers and becomes an effective medium of learning for students.

\section{METHOD}

Web portal for online teacher community already developed earlier through research development with prototyping approaches. This research aimed to evaluate the effectiveness of online teacher community by user acceptance testing approach. Online teacher community website socialized to some of the sample teachers, including a primary school teacher, junior high school teachers and high school teachers around Bali. The samples were given training materials to fill the online teacher community website. In addition, teachers who are members of the sample are also trained to carry out communication (discussion) and the exchange of learning information, particularly information uploaded to the website. At the end of the trial, the teachers involved in the trial are given questionnaire. The questionnaire indicators are software performance, ease of use or operation of the software, user interface of the software to provide guidance to the user, usability or usefulness for the user, and the ease of data exchange process.

The teachers are being sampled provide clues to some of their students to access learning information available on the online teacher community website. Finally, after a sufficient period of time, the students involved in the trial are given questionnaires. The indicators were same with the teacher's questionaires indicators like performance of the software, ease of use or operation of the software, friendliness of software to provide guidance to the user, usability or usefulness for the user, and the ease of data exchange process. But, those indicators viewed from the students' perspective as media users. The students' responses were analyzed qualitatively.

\section{RESULTS AND DISCUSSION}

The web portal of online teacher community can act as a medium that facilitates the cross-subsidy of learning information, whether it was done among teacher, students and between teachers and students. The characteristics of a web portal that were able to pass the limits of time and space was expected to help teachers and students to access learning materials from other schools, both in and outside the region. Teachers and students from schools that had not come forward to access the information learned from other schools that were more advanced. Teachers and students from schools that were quite advanced shared learning information to each other. Thus, teachers and students were expected to create a community of online learning to improve educational quality and equity.

Online teacher community was able to create an organization of teachers, especially teachers of subjects. The main service that was expected from this medium of sharing learning information to improve the quality of education equity. It presented some other forms of information exchange between the information in the form of video, information in the form of images, text and information. This condition could enrich the variety of learning resources. Teachers could choose from a variety of media to support learning undertaken. If the media was considered inadequate to provide the information, the teacher could choose other media to support it. On the other hand, the students could also choose a variety of media to enhance the understanding of the material.

In addition, online teacher community could facilitate connect learning. Connect learning based on connectivism, 
constructivism, and situational learning approach consolidate the concepts that could help to meet the learning needs of the new organized learning scenarios, learner-oriented, communicative, and social, emotional, and situational [6].If the students were confused receive the information from the media, they could choose any other media or even the same media from different sources. In addition, the online teacher community web portal also provided sharing information directly to make comments, ask questions, or provide feedback. If teachers need specific information learning, the teacher could ask to the other teachers. As per custom prevailing in cyberspace (the Internet), another teacher who understands the material would provide answers to their capacity. The same thing would happen among the students and between students and teachers.

The online community web portal of teachers was tested through several tests, such as completion measurement by the experts of media and information technology, the implementation of tests by teacher and students and the examination of learning usage. Generally, the results of the tests were as follows. 1) The web portal online teacher community was good enough to be used as a medium for the sharing information in the form of video, images, or documents, in which the process of uploading videos, pictures or documents were simple, uncomplicated and not too technical, so it could be done by all teachers and no need for special training to them. 2) The web portal online teacher community greatly assisted teachers in learning the information exchange in which the teachers from schools can download information about the learning from teachers in schools that are more advanced. The teachers of the school were quite advanced to share information with teachers learning from schools belonging to other developed to complement each other. Thus, the best teacher community web portal to facilitate cross-fertilization between teachers. 3) Web portal online teacher community petrified students to get lessons, especially if the information study presented was varied. Students who wish to enrich or study ahead of schedule at the school will be well facilitated by the media. 4) The general public, especially the understanding of education issues strongly support the existence of this medium because through this medium they could provide input regarding the lessons or educational policy. The tendency of students in the future hang out more and more in the world of information technology, a little or a lot of the media was to make the students more focused on activities into the learning process.

Currently there were several forums that could facilitate the sharing of information for learning or education in general. The ability of these forums to reach out to the teachers and the administration was limited by geographical region. Indonesia is an archipelago with vast geographical conditions varies greatly across regions. Interregional variations also occur in the population, population distribution and regional income and income residents, so the implications for the performance variation of development, including the development of education. Media in the form of a web portal online teacher community greatly help expand the reach of communication forums. Characteristics of free web portal barriers of time and geographical distance can reach teachers from various regions. In addition, if such an existing forum more likely to work in synchronous, the online teacher community forums tend to work in asynchronous. Therefore, differences in teachers' working time is not a barrier to involve in online teacher communities.

\section{CONCLUSION}

Online web portal teacher community has been successfully implemented and was decent enough to be used as a medium for the sharing information in the form of video, images, or documents. The process of uploading videos, pictures or documents could be done easily, so it did not need special training for teachers. Limited testing indicated that the web portal online teacher community greatly assisted the teachers in learning the information exchange. In addition, the online web portal teacher community provided an opportunity for teachers to introduce scientific work to other teachers and the general public, both to improve the usefulness of the activities and help prevent plagiarism.

Online web portal teacher community petrified students to get lessons, especially if the information about the study were presented vary. Students who want to enrich or study ahead of schedule at the school would be well facilitated by the media. The general public, especially the parents strongly supports the existence of an online web portal teacher community. By utilizing this medium, students are more focused activities into the learning process. Online teacher community is expected to be an organization of teachers, especially teachers of subjects. The main service that is expected from this medium is information exchange to improve the quality of education equity.

\section{REFERENCES}

[1] Ke, Fengfeng \& Christopher Hoadley, Evaluating Online Community Learning, Education Tech Research Dev (2009) 57:487-491 DOI 10.1007/s11423-009-9120-2. Published online 28 February 2009 by Association forEducational Communications and Technology (2009).

[2] Sofos, Alivisos \& Appostolos Kostas, 2009, Pedagogically-Oriented Evaluation Criteria for Web Resources, eLearning Papers, www.elearningpapers.eu, No 17, December 2009, ISSN 1887-1542 
[3] Auvinen, Ari-Matti, 2009, The Challenge of Peer Production eLearning Content, eLearning Papers, www.elearningpapers.eu, No 17, December 2009, ISSN $1887-1542$

[4] Istrate, Olimpus, 2009, Visual and Pedagogical Design of eLearning Content, eLearning Papers, www.elearningpapers.eu, No 17, December 2009, ISSN 1887-1542

[5] Ragbir, Diana \& Permanand Mohan, Creating Reusable Lesson Plans for E-learning using the IMS Learning Design Specification, Education Journal of Education and Development Using ICT, Volume 5, Number 4, 2009, ISBN 1814-0556

[6] Steinert, Anne \& Ulf-Daniel Ehlers, 2010, ConnetLearning - an Answer for the New Challenges, eLearning Papers, www.elearningpapers.eu, No 18, Februari 2010, ISSN $1887-1542$ 